\title{
Wisconsin's IPM Program for Potato: The Developmental Process
}

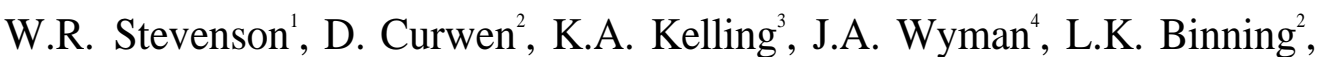
and T.R. Connell ${ }^{2}$

Additional index words. Solanum tuberosum, computer software, IPM team, systems research

Summary. The Wisconsin potato crop is managed intensively through multiple inputs of pesticide, fertilizer, and irrigation. Beginning in 1979, a multidisciplinary team at the Univ. of Wisconsin developed an effective Integrated Pest Management Program to address key management decisions associated with this crop. The program fostered the development of several private IPM businesses and continues to help increase the acceptance of IPM technology by the potato industry. Results of component and integrative research, funded by industry, state, and federal sources, provided the essential ingredients for development of computer software now used for managing the potato crop on $\approx 70,000$ acres $(28,330$ ha) of potatoes in a multistate area. The software helps growers determine the need for and timing of critical crop inputs. By reducing or eliminating unneeded pesticide and irrigation applications, the software helps to improve overall production efficiency. Industry adoption of this software is providing the impetus for development of more comprehensive software that includes additional aspects of potato production as well as the production of crops grown in rotation with potato.

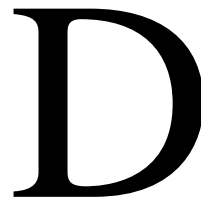

epending on the year, Wisconsin ranks fourth or fifth nationally in the production of potatoes for processing, fresh, and certified seed markets. Potatoes are a key component of the state's diverse agricultural economy, with a value of $\$ 120$ million produced on 68,000 acres (Pratt, 1993). This importance to Wisconsin's agriculture is reflected in research and extension support by the Univ. of Wisconsin (UW) and its College of Agricultural and Life Sciences (CALS).

A team of faculty with research and extension assignments at the Univ. of Wisconsin has engaged in an intensive pest and crop management project with the potato crop since 1979 (Shields et al., 1984). This team has achieved significant progress toward integrating disciplinary research findings into a cohesive and comprehensive management program for the potato crop and the broader farming enterprise that includes crops commonly grown in rotation with potatoes. Wisconsin growers have responded by adopting some, if not all, of the components of this program.

\footnotetext{
The cost of pullishing this paper was defraved in part by the payment of page charges. Under postal regulations, this paper therefore must be hereby marked advertisement solelv to indicate this fact.

University of Wisconsin, Madison, WI 53706.

'Dept. of Plant Pathology.

'Dept. of Horticulture

Dept. of Soil Science.

${ }^{4}$ Dept. of Entomalogy.
} 


\section{Development of Potato IPM in Wisconsin}

The Univ. of Wisconsin-Madison College of Agricultural and Life Sciences has a strong tradition of providing solutions to agricultural problems through a blend of basic and applied research. Coupled with the "Wisconsin Idea" philosophy that the boundaries of the university are the boundaries of the state, the results of agricultural research and new ideas quickly find their way to the farms and communities throughout our state. All too often, however, results of focused single-discipline (i.e., component research) projects are provided to rural audiences without a clear understanding of how this information interacts with other parts of the whole farming enterprise. The integration of this information with site-specific production systems then is left to the clientele, often on a trial-and-error basis. Some of the most focused solutions to long-standing problems fail when attempts are made by clientele to integrate this information with existing practices. In some instances, focused remedies that excel in small field plots actually may have a deleterious effect on other parts of the system.

The UW IPM Program was initiated in 1979 with the assistance of USDA 3d Special Program Funds in response to grower requests for in-depth training in pest and crop management strategies. The Wisconsin IPM program built upon the existing breadth and strength of agricultural programs at UWCALS and delivered this fundamental information to the producers using a hands-on and demonstration approach.

The potato was one of the crops receiv ing early attention in this statewide program. In some respects, this was an ideal choice because: 1) growers traditionally have been progressive and very interested in IPM tactics; 2) the crop is managed intensively with multiple inputs of pesticide, fertilizer, and irrigation; 3) potato is a high-value/high-risk crop; 4) the crop often is grown in environmentally sensitive areas; and 5) historically there has been a strong potato research base at the UW. Intensive research and extension activities have helped to build a strong interdisciplinary team of faculty as well as foster a spirit of cooperation between growers and university personnel. After 3 years ofbuilding a program that involved a system of intensive crop and pest scouting combined with regional and in-field weather monitoring, the field scouting aspects of the program were turned over to private enterprise in 1983. At least six private businesses that specialize in IPM programs dealing with potatoes have evolved and continue to prosper. Recent surveys of the Wisconsin potato growers indicate that $97 \%$ of Wisconsin's growers rely on field scouting to make management decisions, and $46 \%$ now hire an IPM consultant. The interdisciplinary team has continued to work closely with the consultants and grow ers to provide program refinements based on practical inputs from the field.

One important aspect of the Wisconsin IPM program has been the development of specialized computer software to assist growers and consultants in crop and pest management decisions. Initial software development included the PDM (Potato Disease Management) and WISP (Wisconsin Irrigation Scheduling) programs. Roth of these programs then were incorporated into an expanded Potato Crop Management (PCM) program (Stevenson et al., 1989). This more sophisticated software now includes modules for predicting and controlling disease, scheduing irrigation, predicting crop emergence, predicting development and managing harmful insects, and ventilating stored potatoes. Growers and IPM consultants hired by grow ers report sofware use on $\approx 40,000$ ( 16,188 ha) of Wisconsin's 68,000 acres $(27,519 \mathrm{ha})$ of potatoes. Program use also has expanded to neighboring states, where growers report using the software on an additional 30,000 acres $(12,141 \mathrm{ha})$. The software saves grow ers about $\$ 20$ per acre (Connell et al., 1991) by eliminating two to three fungicide sprays for foliar disease control when weather conditions and crop susceptibility do not favor disease development. Estimated savings related to disease control for Midwestern potato growers exceed \$1.4 million per year. Additional savings from software use include reducing rates and improving the timing of herbicide applications, reducing insecticide treatment by targeting vulnerable life stages of economically damaging insects, and reducing irrigation inputs by $10 \%$ to $15 \%$ by matching irrigation inputs to crop demand. Field research has demonstrated that additional savings may be possible when growers use all components of the software fully. Growers and consultants who have used the software for several years appear to achieve the greatest savings.

Grower acceptance of PCM has fostered the ongoing development ofadditional PCM modules covering areas such as record-keeping, fertility management, seedpiece decay, crop canopy development, storage management, and marketing. These developments are backed by extensive field and laboratory research prior to incorporation into PCM.

A promising area of IPM field research now focuses on how to manage better crops such as sweet corn, snap beans, sorghum sudan, and red clover, which are likely to be

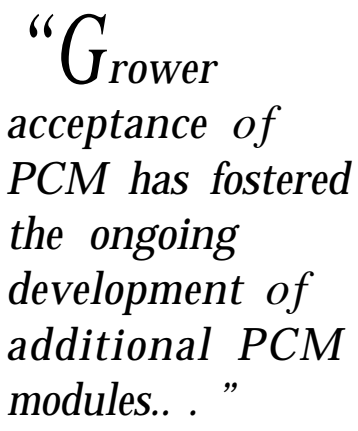

"Grower

acceptance of PCM has fostered the ongoing development of additional PCM dules.. . 


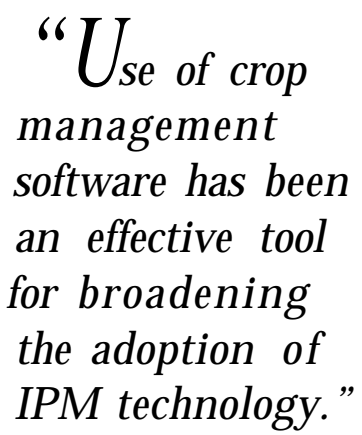

grown in rotation with potatoes. One goal of this research is to understand better how rotational crops affect management of pest problems associated with the potato crop and vice versa. This research will permit the expansion of the current PCM software to include components for selection and management of rotational crops. We anticipate that this will broaden the adoption and use of integrated crop management software in farming enterprises in Wisconsin. In a state with an extensive potato and processing vegetable industry, expansion of the PCM software to include these additional crops is essential to the long-term sustainability of vegetable production systems. The addition- of a rural sociologist to the research and extension team is expected to help identify potential barriers to adoption of new technology. This new information will be especially helpful as focus shifts from a single crop to multicrop systems requiring multiple inputs from growers and field personnel employed by vegetable processors.

The Wisconsin IPM program and focused potato IPM initiatives have attracted state, regional, and national attention. Producers in several potato production areas of the United States now successfully use the PCM software. In addition, cooperative research projects focusing on local adaptation of this software are underway in Oregon and North Dakota. Additional projects to evaluate this IPM software are being discussed with two Canadian provinces.

Use of crop management software has been an effective tool for broadening the adoption of IPM technology. Many of the early goals of the Wisconsin IPM program have been achieved by using computer technology and software on the farm.

\section{Keys to program success}

Creating the team. Dave Curwen was hired in 1963 as a regional vegetable crop specialist and focuses his attention on cultivar evaluation, row spacing, irrigation management, and crop storage. Larry Binning was hired in 1969 to provide leadership in chcemical and cultural weed control. Keith Kelling was hired in 1977 to serve as soil fertility specialist. Jeff' Wyman was hired in 1979 to assume extension/research responsibilities in vegetable crop entomology. He had served in a similar capacity at Univ. of California, Riverside, from 1973 to 1979 with focus on integrated pest management of vegetable insects. Walt Stevenson also arrived in 1979 to assume extension/research responsibilities for diseases affecting vegetable crops. He had served in a similar capacity at Purdue Univ. since 1972, where he gained a working famil- iarity with computer technology and its promise for rapid delivery of research and extension information. Thus, an experienced team was assembled with a mandate to focus on vegetable crop management at a time when IPM implementation was recognized as essential to continuing agricultural profitability and sustainability. The formation of the team also coincided with a generational change in vegetable farm managers, providing a knowedgeable and progressive grower clientele to assist the team in development and implementation of IPM technology. Each team member came from a sufficiently diverse background that they complemented one another without undue overlap. By 1979, all were recognized authorities in their respective fields and had a general hands-on knowledge of crop production practices. Each member brought specialized expertise to the team, and this expertise was recognized and widely used by the Wisconsin potato and vegetable industry. Appointments were split between extension and research, ensuring that team members were involved in extensive field and laboratory research programs (component research) that were closely tied to their extension programs. Combined research/extension responsibilities enabled the team to spend considerable time together in travel, discussion, planning, and meetings. All members were comfortable working as a team and were willing to share team responsibilities along with any credit or criticism directed to the team. It should also be noted that the team approach to programming and problem-solving is inherent to the Wisconsin Cooperative Extension Service and its subprogram committee structure.

USDA/UW-CALS/UW-Extension

funding. Funding for statewide extension programming in integrated pest management first became available to Wisconsin in 1979. These formula funds were critical in focusing programming efforts in IPM and in assembling an effective plan for multidisciplinary programs. While specialists from several disciplines traditionally had participated in grower meetings and held days, the approaches taken generally were not multidisciplinary or integrated. For the first time, funds were available to encourage specialists to begin thinking as an extension team rather than as disciplinary extension specialists. These funds were also critical in developing computer literacy within the IPM team. The need to develop multiple expertise within the framework of a single computer-based system was very beneficial in achieving overall program integration. The USDA-Extension funding arrived at a critical juncture in team development and this funding continues to support IPM efforts. 
Extension funding was used to hire program specialists at the Master of science (MS) level alongwith computer programmers. The program specialists worked closely with the faculty IPM team and focused their attention on developing specialized IPM programs for targeted commodities, including potatoes. The hiring of computer programmers was an essential early component of the IPM program in developing one of the major delivery mechanisms of IPM information. By permitting the IPM team to make these hires, UWCALS and UW-Extension administration gave the team a vote of confidence and a chance to develop a coordinated and multidisciplinary IPM program. In retrospect, this helped to gel a group of individuals from several departments into a team willing to commit time and energy to IPM research and extension programming. UW-Extension administration continues to provide programmatic support of IPM activities.

For successful implementation in the commercial production arena, integrated programs such as PCM must be based on a solid and carefully constructed foundation within each of the individual disciplines involved in production. Disciplinary research has generated individual components of PCM, such as disease prediction (Pscheidt and Stevenson, 1986; Stevenson, 1993), insect modeling (Walgenbach and Wyman, 1984a), economic thresholds (Shields and Wyman, 1984; Walgenbach and Wyman, 1984b), weed development (Wiese and Binning, 1987), irrigation scheduling (Curwen and Massie, 1984), nutrient management (Kelling and Wolkowski, 1991; Kelling et al., 1992; Kelling and Wolkowski, 1992), and environmental impacts (Wyman et al., 1985). Without this research base, the integrated PCM software would not meet the essential needs of the production system. This essential phase of component research is long-term and ongoing, involving the efforts of graduate and undergraduate students and specialists. UWCALS continues to support component and integrative research efforts through Hatch funding. Recent evaluation and planning efforts within UW-CALS have placed emphasis on programs that demonstrate linkages between disciplines and research areas. The potato IPM program has been identified as a effective model program. This recognition will be reflected in continued and potentially increased funding within the college.

USDA regional IPM project fund ing. Beginning in 1987, a series of research projects were submitted by the UW-Potato IPM Team to the USDA Regional IPM Program for review and funding. Funding for the first of these projects, conducted during 19871988, allowed the team to begin integrating the results of successful field research programs (component research) into 3 comprehensive management program. The product of this research was the development and release of the Potato Crop Management (PCM) software in 1989. The effectiveness of the integrated model was evaluated in large field plots at the Hancock Agricultural Research Station, located in central Wisconsin (integrative research). Somewhat surprisingly, this was the first time this team had worked together on such a large-scale research project. During the integrative research phase, advanced $\mathrm{PhD}$ students and postdoctoral trainees were hired to coordinate the large-scale field research trials and facilitate interdisciplinary cooperation. This hiring ensured stead! progress of the project and allowed the team to focus on planning and evaluation activities. The team met regularly throughout the year to make management decisions regarding the research and the management of the potato crop. The team recognized the importance of integration and, through results achieved during the first 2-year year block of funding, began to refine a commercially acceptable system for potato crop management (Connell et al., 199 1). This system we then evaluated and fine-tuned during a second 2-year cycle of funding (1989-90). Throughout this 4year period, key growers were helpful in providing advice and direction. In some cases, this feedback led to additional component research, whereas in other cases grower experience helped to fine-tune further integrative research objectives and approaches.

In 1991, Wallendal Farm Supply, Inc., a highly successful potato and processing vegetable farm in central Wisconsin, offered the Potato IPM Team an opportunity to use a 25-acre field with irrigation for long-term field research studies. This was an opportunity to expand the research focus on potato to include several crops commonly grown in rotation with potato (sweet corn, snap beans, red clover, and sorghum-Sudan). One of-the key research objectives was to observe how rotational crops affected various aspects of potato production, including irrigation, fertility, and pest problems (diseases, plant parasitic nematodes, weeds, and insects). A companion objective was to observe how a potato crop affects management of the rotation crops in 2and 3-year rotations. It is important to emphasize that funding from the USDA Regional IPM Program was an important catalyst for these expanded integrative studies. This funding came during a critical period and enabled the Potato IPM Team to maintain their focus and to expand their efforts. Funding provided by this program prompted additional support from the Wisconsin potato and vegetable industry and from individual growers.

\section{"F}

E or successful implementation in the commercial production arena, in team ted programs such us

PCM must be based on a solid and car efully constructed foundation within each of the individual disciplines involved in production." 


"A strong
camaraderie bus
developed be
tween the potato
industry and
university re
searchers/exten-
sion specialists...
This association
has fostered a
team concept that
includes grower
interaction and
ageneral atti-
tude of partner-
ship.. ."

More-recent funding from USDA CSRS/ES is providing information on the process ofadoption of new technology by client\&. Peter Nowak, UW-Rural Sociology, is joining the potato IPM team and conducting a focused study on potential barriers that will affect the adoption of new IPM technology at both the farmer and vegetable processor levels. The information gained in this study hopefully will enhance future adoption of the technology developed by our IPM team.

Industry funding. Beginning in the mid- 1970s, the Wisconsin Potato Industry began a checkoff program that contributed about $\$ 20,000$ for research on production problems experienced by the industry. By the mid- 1980s, the level of funding increased to $\$ 80,000$ and, in 1993 , funding reached $\$ 180,000$. The Wisconsin Potato Industry Board designates a research committee to meet regularly with UW-CALS faculty to review the problems facing their industry and to encourage the preparation ofresearch proposals addressing these problems. The research committee then reviews these proposals and recommends which proposals should be funded. While funding for a specific project rarely exceeds $\$ 15,000$, this funding often serves as seed money to initiate new projects and to leverage additional funding from a wide array of funding sources. While growers normally fund problem-oriented disciplinary projects, they also have provided funding of critical importance in underpinning the interdisciplinary effort, such as maintenance of a statewide weather network and refinement of integrated software. Researchers report their findings to the industry research committee and to the industry as a whole during winter educational meetings.

A recent development in industry f\&ding of- potato research is the planning for a "potato excellence fund" consisting of a $\$ 1.25$ million endowment provided by growers and allied industry who wish to provide resources in addition to the normal checkoff. This fund will be established in an interest-bearing account at the Univ. of Wisconsin Foundation. The fund will be managed cooperatively by growers, industry representatives, and the university. A portion of the annual interest will be used to address long- and short-term concerns of the industry through funding for graduate students, technical support, and special high-impact projects. The remaining interest will be reinvested into the fund to offset inflation. The "potato excellence fund," developed at the initiative of key growers, is indicative of the mutual respect that has evolved over the past many years of interaction between the college and the potato industry. The level of proposed support and the way in which the support will be distrib- utcd will help to maintain team interest and focus.

Grower interaction. A strong camaraderie has developed between the potato industry and university researchers/extension specialists and has been a major key to success. This association has fostered a team concept that includes grower interaction and a general attitude ofpartnership between the university and the potato industry. The Wisconsin potato industry maintains close contact with the IPM team through a series of winter educational meetings and summer field days. At these meetings, growers hear from research and extension specialists regarding up-to-date reports of current research, reviews of seasonal production problems, and discussions of future industry trends, issues, and needs. Virtually all Wisconsin growers attend at least one of these meetings or field days per year. In addition to Wisconsin attendees, it is common to attract attendees from Michigan, Illinois, Iowa, Minnesota, and Canadian provinces.

Concepts and products tested in small plots on university research farms frequently have been verified through further testing on grower farms. This essential ingredient for both component and integrative research has strengthened the ties between the university and industry. The potato industry cooperates closely with university research and extension faculty by providing land, equipment, and financial resources to ensure success of large field plots.

Because growers contribute financially to research and extension programs, they are keenly aware of the need for visible, definable, and measurable progress from each research project. The industry feels a partnership with the research and extension team as goals arc defined, research is conducted, and progress is made. In addition to frequent interaction with growers, the IPM team also interacts frequently with the processing industry, e.g., Frito Lay, Inc., Ore Ida Foods, Inc., Sunspiced, Inc., and others, to answer questions, solve problems, provide education for their production employees, and cooperate in research projects. Extension appointments of team members allow them to spend considerable time with growers on their farms evaluating problems, formulating solutions, and testing ideas and concepts. Dialogue with individual growers maintains a close association with the potato industry. The potato industry is extremely complementary of the IPM programs and research that have been ongoing for the past 14 years. They note that pesticide inputs are declining, yields and quality are increasing, and that they are increasingly competitive with other production areas. 


\section{Conclusions}

The Potato IPM Team has been successful in obtaining research and extension funding and in achieving its stated objectives during the past 15 years. The team has developed and delivered useful information to a receptive grower audience. By including growers and affiliated industry representatives as participating team members, there is a sense of pride and ownership of IPM programs within the entire Wisconsin potato industry. This, in turn, has helped to establish a high esprit de corps among the team and fostered extensive cooperative research and extension efforts. Team efforts have been lauded by administration and noted by other disciplines within UW-CALS. Granting agencies have recognized multidisciplinary team efforts with funding for both research and extension programming.

Growers and the entire potato industry have been quick to adopt new IPM practices that reduce pest problems, reduce crop in puts, reduce adverse environmental impacts, increase crop performance, and increase their competitiveness with other production areas. Their adoption of new computer technology and requests for new, more-comprehensive, crop management software has spurred further software development. Grower use of computer software has brought a unique focus to the overall IPM program in Wisconsin.

The complexity of objectives is increasing as the team moves from a single crop focus to a broader perspective of the farming enterprise. Recent team additions of an agricutural economist and a rural sociologist will help fill current gaps and provide coverage in economics and technology adoption that have been lacking in past efforts.

\section{Acknowledgment}

We gratefully acknowledge the support of the many undergraduate and graduate students, postdoctoral trainees, and research specialists who worked with program development; the computer programmers who created the Potato Crop Management software; growers who contributed time and facilities for program testing; staff of the UW Agricultural Research Stations, where much of the component research was conducted; count) extension agents in key areas of Wisconsin potato production; and independent crop con sultants, who continue to provide input.

\section{Literature Cited}

Connell, T.R., J.P. Koenig, W.R. Stevenson, K.A. Kelling, D. Curwen, J.A. Wyman, and L.K. Bin ning. 1991. An integrated systems approach to potato crop management. J. Prod. Agr. 4(4):453460 .

Curwen, D. and L.R. Massie. 1984. Potato irrigation scheduling in Wisconsin. Amer. Potato J. 61(4):235-241.

Kelling, K.A., C.R. Grau, D.I. Rouse, A.E. MacGuidwin, and D. Hero. 1992. Nitrogen needs of potato following forage legumes. Amer. Potato J. 69(9):590.

Kelling, K.A. and R.P. Wolkowski. 1991. Influence of potato variety on petiole nitrate- $\mathrm{N}$ critical levels. Amer. Potato J. 68(9):620-621.

Kelling, K.A. and R.P. Wolkowski. 1992. Interaction ot potato variety and $\mathrm{N}$ rate on yield, quality and petiole nitrate nitrogen levels. Proc. Wisconsin Annu. Potato Mtgs. 5:23-30.

Pratt, L.H. 1993. Wisconsin agricultural statistics. Wisconsin Dept. of Agr., Track and Consumer Protection, Madison.

Pscheidt, J.W. and W.R. Stevenson. 1986. Conparison of forecasting methods for control of potato early blight in Wisconsin. Plant Dis. 70(10):915920.

Shields, E.J., J.R. Hygnstrom, D. Curwen, W.R. Stevenson, J.A. Wyman, and L.K. Binning. 1984. Pest management for potatoes-A pilot program. Amer. Potato J. 61(8):508-516.

Shields, E.J. and J.A. Wyman. 1984. Effect of defoliation at specific growth stages on potato yields. J. Econ. Entomol. 77(5):1194-1199.

Stevenson, W.R., L.K. Binning, J.A. Wyman, D. Curwen, G.J. Rice, J.R. Zajda, J.E. Smidl, R.M. Thorson, and R. W. Schmidt. 1989. PCM-The integrated systems approach to potato crop management. User guide for IBM and IBM-compatible personal computers, Version 1.1. UW-Madison IPM program.

Stevenson, W.R. 1993. IPM for potatoes: A multifaceted approach to disease management and information delivery. Plant Dis. 77(3):309-311.

Walgenbach, J.F. and J.A. Wyman 1984a. Colarado potato beetle (Colcoptera: Chrysomelidae) development in relation to temperature in Wisconsin. Ann. Entomol. Soc. Amer. 77(5):604609.

Walgenbach, J.F. and J.A. Wyman. 1984b. Dynamic action threshold levels for the potato leafhopper (Homoptera: Cicadellidae) on potatoes in Wisconsin. J. Econ. Entomol. 77(5):1335-1340.

Wiese, A.M. and L.K. Binning. 1987. Calculating the threshold temperature of development of weeds. Weed Sci. 35:177-179.

Wyman, J.A., J.O. Jensen, D. Curwen, R.L. Jones, and T. Marquardt. 1985. Effects of application procedures and irrigation on degradation and movement of aldicarb residues in soil. J. Environ. Tosicol. \& Chem. 4:641-651,
"By including powers and of filiated industry representatives as participation, team members there is a sense of pride and ownership of IPM programs. .. " 